\title{
POESIA GAUCHESCA PLATINA: PERSPECTIVA NARRATIVA E IDEOLOGICA
}

\author{
Cecilia Teixeira de Oliveira Zokner **
}

\begin{abstract}
Raconter une histoire implique forcément une certaine position du narrateur par rapport à cette histoire. Michel Raimond.
\end{abstract}

Em 1872, com o propósito evidente de expressar verdades, são publicados Los tres gauchos orientales (crônica da revolução de Aparício) e Martin Fierro (testemunho sobre o gaúcho). Documentos histórico-literários dos países do Prata, nasceram ambos, como tambén toda a poesia gauchesca primitiva, de "uma necessidade combativa", 1. de um proselitismo político, de um compromisso social. E, tanto a obra de Lussich, como a de Hernández, no dizer de Angel Rama, encerra "o grande periodo da poesia gauchesca política" 2 que se iniciara com Hidalgo e Ascasubi. Mas, ao mesmo tempo que marcam o fim de um ciclo literário, constituem, também, ainda no dizer de Angel Rama ${ }^{3}$ o início das "lamentaçōes individuais, testemunho de que se quebrou o sistema comunitário das origens e que portanto se impôs também aqui no rio da Prata a fragmentação individualista que trouxe o li-

1 SANSONE DE MARTiNez, Eneida. Prólogo. In LUSSich, Antonio D. Los tres gauchos orientales, Montevidéu. Ministério de Instrucción Pública y Previsión Social, 1964, p. XIX.

2 RAMA, Angel. Introducción. In LA POESTA política; Hidalgo, Araucho, Ascasubi, Lussich, Hernandez. Montevidéu, Ed. Arca, 1968, p. 245.

3 Ibid. p. 245

* Este trabalho é o desenvolvimento da aula Martin Fierro: consciencia de classe do programa Manifestaçoes Literáriał da Região Sul: Literatura Gauchesca, parte do Curso de Especialização em Literatura Brasileira, rea. lizado no Setor de Ciências Humanas, Letras e Artes da Universidade Federal do Paraná em 1974.

* Cecilia Teixelra de Oliveira Zokner é Doutor em Literatura Comparada pela Faculté des Lettres et Sciences Humaines de Bordeaux, Franca, com a tese L'influence de la France dans l'oeuvre de Fialho de Almeida (1967) que traduziu e foi publicada, em 1974, pela Imprensa da Universidade (Paraná). Colabora na revista Letras desde 1969 e, atualmente, leciona Literatura Hispano-Americana na Universidade Federal do Paraná. 
beralismo econômico e que há de triturar onde quer que seja a esperança de uma comunidade humana abroquelando as suas partes integrantes no individualismo, esporadicamente no casal, voluntariamente na família". 4

Partindo desta observaçāc de Angel Rama constatamos que de fato, os diálogos de Los tres gauchos crientales constituem, na primeira pessoa plural, a expressão de homens que lutam por um ideal político e que, ao abstrair o objetivo da luta, as experiências vividas nessas lutas e as esperanças patrióticas passam a se expressar numa subjetiva e fracassada primeira pessoa singular; e que ao contrário, o monúlogo de Martin Fierro se inicia numa primeira pessoa subjetiva e fracassada, ao exprimir-se na primeira pessoa plural, nela incluindo todos os gaúchos, traduz uma conscientização a respeito das tradicionais posições das sociedades constituidas: dominio de uma classe sobre a outra.

Aa analisar esta mutação do narrador, a sua auto-definição como gaúcho versus os demais membros da sociedade, a sua posição na dicotomia resultante das forças que se the opöem, foi possivel constatar, também, que não se trata de uma simples opção de perspectiva narrativa 5 uma vez que nela estão contidas, emergentes, as posiçōes ideológicas de um tipo social efêmero e eloqüente. E o que nos proporemos demonstrar.

Na obra de Lussich, o gaúcho Luciano Santos, "metido en un matorral" 6 escutou e registrou "a prosa" dos três gaúchos "Pa recordarlo algún dia/como un cuento nacional" 7 O diálogo, como já o escla. rece 0 subtítulo 8 se desenrola na primeira pessoa singular versus usted e, eventualmente, na primeira pessoa plural representando os próprios interlocutores e o grupo social a que pertencem. Neste trabalho, a primeira pessoa singular terá interesse apenas quando expressāo de "lamentaçōes individuais"; a primeira pessoa plural quando representar os três interlocutores e seus correligionários.

Os interlocutores, "gauchos orientales" se encontram no seu habitat, a campanha uruguaia e tratam da Revolução Oriental chefiada pelo Coronel Timoteo Aparicio. A obra de Lussich seguindo as pegadas

4 alamentaciones individuales. testemonio de que se ha roto el sistema ca munitario de los origenes y que por lo tanto se há impuesto tamblén nqul en el rio de la Plata la tragmentación individualista que há aportado el llberalismo economlco y que ha de triturar por doquier la esperanza de una comunidad humana, abroquelando a sus partes integrantes en el individualismo, espora. dicamente em la pareja, voluntariamente en la tamilias.

5 A expressto perspectira narrativa ef usada no sentido que the da Oscar Tacea em las roces de la novels. Madrid. Gredos. 1973. D. 71.

6 LUSSICH, Antonio D. Los trie kauehos orientales. Mantevidéu. Ministéri, de Instrucción Pública y Previsión Social, 1964. p. 96.

7 Ibid., p. 71.

8 adialogo entre los palsanos Jullan Gimenez, Mauricio Baliente y José Centurións. 
do diálogo gauchesco 9 traz as formas essenciais dessa estrutura; cumprimento, resposta, convite para desensilhar, para matear, pergunta que dá lugar ao desenvolvimento do tema central, convite ao churrasco, episódio secúndário, continuaçāo do tema central, despedida dos amigos, final. 10 Segundo Eneida Sansone de Martinez, o sustrato de todo diálogo gauchesco é um relato cuja monotonia é quebrada pelas interrupções e comentários dos interlocutores o que permite estabelecer, em todo diálogo, duas partes bem definidas: o relato ou relatos a cargo dos protagonistas e as conversas que compreendem cumpri. mentos interrupçōes, brincadeiras, etc. 11

No diálogo dos três gaúchos orientais a primeira pessoa plural aparece nas fórmulas de cortesia e no desenrolar do tema central. Assim, são expressos na primeira pessoa plural a razão que motiva o encontro e os convites tradicionais: " $Y$ no me quiero largar/Sin que hablemos este dia" (p. 11) 12 "y gorgoriemos un taco/ Por la cáida del tirano" (p. 56), "De matiar iratémos pués" (p. 13), "Chupemos por despedida" (p. 95), "Perdimos en la merienda/Lo mejor de la milon$\mathrm{ga}^{\prime \prime}$ (p. 50).

O tema central ć a revoluçāo de Aparício. A primeira pessoa plural passa então a englobar, além dos três interlocutores, os seus correligionários, 13 aqueles citados nominalmente e todos os que lutaram pela divisa branca. 14

Enquanto as fórmulas de cortesia são expressas no presente, ao tratar do tema central, as formas verbais se apresentam nos tempos passado, presente e futuro.

No passado são relembradas as lutas "Cuando fimos a la Unión/ A sitiar Montevidéu" (p. 33), "Después vino Ceverino/Alli rayamos los pingos" (p. 19), "Tamién con Carabajal/Nos topamos lindamente" (p. 19); os contra ataques "Pero pronto nos reunimos/Otra vez al grán montón" (p. 22); as vitórias "Y a poco andar lo golpiamos/Al tan mentao Frenedoso" (p. 18); as retiradas "Que retirarnos tuvimos" (p. 22); o exílio "Seis años de emigración/en suelo estraño tuvimos/Pe. nurias, males sufrimos" (p. 15).

Em tempo presente é constatada a situação em que encontram

9 Pura Enclda Sansone de Murtinez kLas possibilidades expressivas del dialogo Gauchesco fueron descublertas $y$ en cierto modo fljadas por Hidalgos (Ver SANBONE DE MARTINEZ, p. XXIII).

10 Sobre a estrutura do dílogo gauchesco ver SANSONE DE MARTINEZ p. XXIV.

11 Ibid. p. XXIII

12 LUSSICH, Antonio D. Los três gadchos oriontales. Montevideu, Ministério de Instrucción Pública $y$ Previstón Social, 1964. Os números de páginas que zeguem as citações correspondem todos a esta obra.

13 Quando narram as batalhas travadas e, entåo, os feitos herólcos de seus companhelros.

14 C.3 contendores eram designados por blancos e colorados, tradicionals partIdos politicos uruguaios que se opóem desde 1838, duta de seu aparecimento. Ver Marcel Niedergang. Les 20 Amériques Latinod. Paris, Beull, 1969, p. 224. 
os très interlocutores e todos aqueles que participaram da luta: "Y boy disgraciaos y vendidos" (p. 15); "Ansi es mejor que prosiemos/ De nuestra tan triste suerte" (p. 13); "Y hoy de nuevo la nación/Vuelve a cerrarnos la puerta" (p. 14).

As dúvidas quanto ao destino da pátria e do próprio destino são expressas no futuro. Semanticamente, de très formas: um futuro imediato, indeciso. sem muitas ilusöes, é como que um prolongamento do presente e mesmo, do passado: "De campo nos mudaremos" (p. 13); "Y con la pata en el suelo/Al lin nos hemos de ver" (p. 73); Os demais exemplos já indicam que, em relação com o futuro, a posição ideológica entre os interlocutores divergem. Opondo-se ao pessimismo do interlocutor $\mathbf{A}$, a confiança do interlocutor $\mathbf{C}$ é de tal modo pueril que pade scr confundida com a ironia: "Vamos a quedar mamaos/Porque ya la paz tendremos (p. 32); "Mas hoy creo han de pagar/Y las botas nos pondremos" (p. 32).

O futuro remoto para o interlocutor $C$ apresenta-se pacífico e fraicrnal: "Ansi orientales seremos" ( $p$. 78); "Que semos unos y hermanos" (p. 82); "en que unidos viveremos" (p. 71); "Y juntos trabajare-

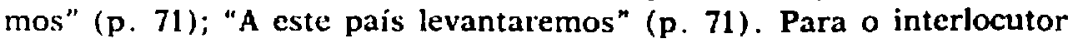
$\Lambda$. no cntanto, as promessas " $Y$ como fin de grandezas/Dicen por av, que tendremos/Un dia pa que votemos" (p. 81) não convencem. Está. inclusive, absolutamente certo de que haverá represálias: "Como po dremos vivir/Trataos de un modo tan cruel?" Represálias estas que levaräo, uma vez mais, às armas: "Al flamenco apelaremos" (p. 79), "Y entreveraos saliremos" (p. 79).

O futuro expresso no tempo presente também apresenta duas pusiçōes: a do interlocutor $\mathbf{C}$ pregando a paz: "Colguemos pues nuestras ármas" (p. 71); "Alcemos los campamentos" (p. 69); "En un cañadon echémos/Las ármas de un cruel pasao" (p. 78); "Tratemos pues de ampararlo [al país]" (p. 78); a do interlocutor A certo das represálias, aconselhando o exílio: "Y hoy disgraciaos y vendidos/Como hacienda por dinero,/Volvemos al estrangero" (p. 15) "Ni van a dejar pa casta/Si nos agarran mansitos" (p. 28).

A primeira pessoa singular expressa a miséria em que se encontram: "Viejo, amolao y desnudo" (p. 75), "Estoy hecho un ay de mi" (p. 29), "Y yo que ya me he quedao" (p. 74), "Yo no sé lo que es

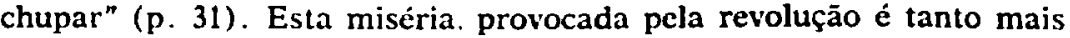
sofrida quanto já houvera posses interiormente: "Un pión yo tenía (p. 32), "Yo tuve ovejas y hacienda" (p. 16).

Sobretudo, a primeira pessoa singular expressa um lirismo amoroso, fraternal e patriótico: "Pucs de dicha me comuevo/Al hablar de mi querida" (p. 33); "alma de amor partida" (p. 17); "Y yo cómo he de olvidar/ A los que han muerto a mi hermano? (p. 15); "Y de mis ojos senti/Dos lágrimas refallar" (p. 71). Isto, ao sentir os estragos da guerra.

A estrutura narrativa en El gaucho Martín Flerro é simples: Martin 
Fierro é o narrador, em primeira pessoa e, ao mesmo tempo, o personagem principal 15. Em determinado momento cede a palavra ao Sargento Cruz. Nas estrofes finais do poema surge, imprevista, a incursão de um narrador que sc torna "responsável" pela narrativa da qual, atć entāo, fora transmissor: "En este punto el cantor/Buscó un porrón pa consuelo/ Echó un trago como um cielo/Dando fin a su argumento" (p. 88).16 A partir daí, onisciente, continua, cronologicamente, a rclação de que aconteceu a Martin Fierro e a Cruz: "Cruz y Ficrro, de una estancia/Una tropilla se arriaron/Por delante se la echaron,/Como criollos entendidos, /Y pronto sin ser sentidos/Por la frontera cruzaron. "Y cuando la habian passao/Una madrugada clara/Le dijo Cruz que mirara/Las últimas poblaciones/ $Y$ a Fierro dos lagrimones/Le rodaron por la cara" (p. 88). Onisciente, até certo ponto porque. a partir do momento $\mathrm{em}$ que Martin Fierro e Cruz entram no deserto, o narrador confessa nada mais saber deles: "No sé si los habrán mucrto/En alguna correria, /Pero espero que algún dia /Sabré de ellos algo cierto" (p. 89). Então, o narrador assume a posição de testemunha: "Males que conocen todos/Pero que naides contó" (p. 89).

Da narrativa de Martin Fierro sobressaem, "classicamente gauchescos", 17 cinco temas que constituem a sua experiência vivida "sus trabajos, sus desgracias, los azares de su vida de gaucho" 18: o tema da paz, da opressāo, da agressāo, da clandestinidade, do afrontamento" "tuve en mi pago en un tiempo/hijos, hacienda y mujer" (p. 24), "Ansi empezáron mil males" (p. 24). "Yo juré en esa ocasión/Ser más malo que una fiera" (p. 46), "Y como con la justicai/no andaba bien por alli/Monté y me encomendé a Dios/rumbiando para otro pago" (p. 55), "En que les gané cl tirón/Sin aguardar voz de preso" (p. 62).

Ao narrar a sua vida de gaúcho, Martin Fierro constata que existe um paralelismo entre os seus "azares" e os que são sofridos por elementos que designa paisano, el pobre, el gaucho que llaman vago, un gaúcho. 19

15 Ver o diagrama do narrador em Martin Fierro e em L. vaelta de Martin Flerro na obra Ias voces de la novela de Oscar Tacca, p. 134135. (Madrid, Gredos, 1973).

16 HerNandez, José. Martin Fierro. Buenos Aires, Ciordia, 1975. Os nú. meros de páginas que geguem as citagóes correspondem a esta obra.

17 Expressāo usada por Eneida Sunsone de Martinez ao abordar a temáticn de Los trís gauchos orientales. Considera temas gauchescos: samor, la des. gracia, la burla, la patria, el caballo, la mujer, la guerra, la soledad, la muertes entre outros. (SANSONE DE MARTINEZ, p. XXVI).

18 Palavras de José Hermandes em carta a José Zoilo Miguenz. Ver HeRNaNDEZ, José. Martin Flerro. Buenos Aires, Losada, 1972, p. 21.

19 Os demiis gaúchos também possuiram ranchos, fllhos e mulher. Tambem para eles o servico militar, os cantós.3, assim como o crime, será o iniclo da vida de matreiro: Aunque muchos cren que el gallcho/Tiene una alma de reyuno,/No se encontrará ninguno/Que no le dueblan las penas, (p. 49). Dai a constataça que cel gaucho que llamnn vago/No puede tener querencia* (p. 55). 
Designaçōes estas que também ihe podem ser conferidas, como na verdade o são, o que significa ser ele, Martin Fierro, e os demais gaúchos, usando a sua própria cxpressão "Astillas del mesmo palo" (p. 84). Do reconhecimento deste fato 30 surge o uso da primeira pessoa plural (estabamos riunidos" p. 23), do pronome nos ("con otros nos mesturaron", p. 27) e do pronome uno ("Mas no debe aflojar uno/Mientras hay sangre en las venas" p. 49) ou "Si uno aguanta es gaucho bruto/, Si no aguanta es gaucho malo" (p. 57).

Em Los tres gauchos orientales os interlocutores se autodefinem como gauchos no tradicional estilo 21 do cantar gauchesco, isso é, se auto elogiam e sobretudo, no que se refere à astúcia e à capacidade de captar as manobras políticas enganosas: Julián "yo soy un gaucho redondo" (p. 23) 22; Baliente: "Soy gaucho muy albertido... Siempre estoy bien empilchao" (p. 12), "que soy gaucho inteligente" (p. 48), "Ansi soy yo, dibertido/Pelo cuando el lomo hincho,! Zambullo como el capincho/ Que de cuca es peresguido!" (p. 27), "Soy gaucho lindo y parejo,/De bosal. laso y coyunda./Poco me enriedo en la junta/De mi reborber! canejo! (p. 31). Ao designar os interlocutores, também usam a expressāo gauchc: "A ese gaucho paquetaso/Le gusta ensillar güen pingo" (p. 30), "Pero si usted es gaucho rudo...,p. 68). 23

E os chefes, os comandantes. quando valentes, são também chamados gaúchos: "Don Julián! Solo un dotor! Salió guapetón y listo, $/$ ! Pocos iguales he visto! Es pierna y muy superior; /Güen gaucho al par del mejor" (p. 24). Quando a palavra não aparece, textualmente, a descrição, em que se evidenciam as caractcrísticas gaúchas definem. da mesma forma, o tipo gaúcho como é o caso dos versos sobre o Coronel Arrué (p. 25).

Se os pronomes e os verbos de primeira pessoa plural englobam os correligionários e se a designação gaúcho serve não apenas para designar-se a si mesmo e aos interlocutores, mas, cventualmente, para designar os chefes, a oposição se manifesta em relação aos "colora-

20 No canto VII define o gaúcho sob o ponto de vista da clels; como obser. vador, guarda, entăo, uma certa distancia, Mas, de pronto, se engloba, so insere no grupo, no tipo que define, usando o pronome uno e logo o pronome Yo.

21 Tradição que se prolonga até os dias de hoje. Ver, por exemplo og poemas de Seralim Garcia, José Larralde.

22 LUSSICH.

23 Julian Gimenez referinda-ge a Jose Centurión.

24 Como partidario puros (p. 83), عPa el que ha sido blanco puro/? que hacer en trance tan duro?s $(p, 14)$, Cree usté que puede haber yunta/Con partidn tan opuesto? (p. 17i), cGritarans! es enemigo!/! Es blanco - salga pa Juera!* (p. 79), Cuando nó. viene un cantor/Y en la guitarra le canta:/Ya el blanco jo se levrnta/Y aqui vive de farors (p. 80). cLas clavijás le sujetan/Por se: blanco y nada mág; (p. 80). ¿Diay salió el grupo gloriosos? (p. 18). 
dos" 24 e ao plumerio 25. Ou seja, claramentc, no binômio A opressor X $\mathbf{B}$ oprimido em que A (partidários dos colorados) vencedores, cheios de promessas e, aparentemente, de boas intençōes, sāo suspeitos de não cumprirem o prometido e em que $\mathbf{B}$ (partidários dos blancos soldados ou coronéis) devem aceitar uma derrota que foi assinada pela cúpula.

Martin Fierro também se define no "tradicional estilo de cantar gauchesco": "Soy gaucho, y cntiendaló/Como mi lengua lo esplica:/ Para mi la tierra es chica/Y pudiera ser mayor; /Ni la víbora me pica/ Ni quema me frente el sol" (p. 18). Todavia, além destes auto-elogios habituais que se espalham pclo seu monólogo, 26 no que insiste, realmente, para definir o gaúcho é na sua condição de pária de um grupo social 27 que se compũe do alcalde, juez de paz, coronel, cabo, sargento, los que mandan, ministro, policia, milicla.

A oposiçāo entre os dois grupos se manifesta, claramente, no binômio a opressor $\mathbf{X}$ b oprimido em que a manda, bate, rouba, atingindo assim, um razoável status económico-social e em que b obedece, apanha, trabalha, numa trajetória que vai da pobreza à miséria.

A presença de um poder (arbitrário) que se origina, respectivamente de um partido vencedor c de seus políticos e de um Estado constituído irá favorecer uma situação em que $\mathbf{A}$ e a serāo oprimidos por B e b.

No entanto, para os interlocutores de Los tres gauchos ortentales (nós), o opressor (eles) é a autoridade do partido oposto, mas também qualquer elemento do partido oposto. Para Martin Fierro e os demais gaúchos (nós), o opressor é o hierarquicamente superior.

\section{A opressor,

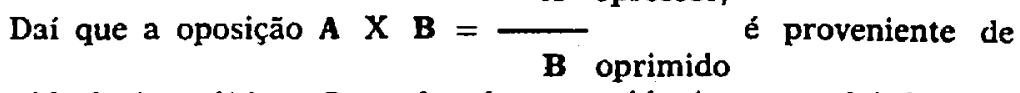
uma ideologia política. O ter lutado e vencido (no passado) leva os interlocutores de Los tres gauchos orientales a se descobrirem como força operante 28 que poderá, inclusive, vir a mudar a situação dos colorados no futuro. Mas, tudo leva a crer que se houver mudança, B

(B X A consequientemente $\longrightarrow$ ) a hierarquia será mantida.

A

25 «Pero pa más estruplcio/Los letraos be nos volvieron. (p. 23), wa gente que llaman śbbiass p. 24), Son los que untan el bolsico/Con la sangre de este paiss (p. 26). TTíne razón y no miente:/Hublera sldo otra cosa/sin los enriedos y prosa/Que nos trujo esa tal gente./Que se llama intellgente $X$ nos quilere embosalar (p. 27).

26 Entre outros: Naides me pone el pie encimas (p. 17), slempre me tuve por glleno, (p. 18), eNunca fui saucho domido/Slempre pronto, siempre listor (p. 45).

27 Sobretudo nos cantos VIII e IX.

28 Ver Angel Rama. 
Na dicotomia a $\mathbf{X} \mathbf{b}=\frac{\mathbf{a}}{\mathbf{b}}$ a oposição se verifica entre clas-

ses sociais. A que detém o poder econômico e seus defensores (ainda que economicamente fracos) e a que participa, com o seu trabalho, para que este poder se mantenha. Martin Fierro - humilhado, explorado, perseguido - se conscientiza da existência de nāo apenas uma, mas de vázias vítimas da discriminaçāo hierárquico-social (presente). Se ocorrer a mudança necessária. esta será vertical, da base para o ápice.

Para os interlocutores de Los tres gauchos orientales é aceitação ou rejeição de uma sorte política $\mathbf{2 9}$. Para Martin Fierro, a compreensão de um estado de coisas prevalecente que se tornou inaceitável.30

A perspectiva ideológica de Los tres gauchos orientales, expressa pcla primeira pessoa plural é substituida pelo lirismo em direção à fragamentaçāo individualista de que fala Angel Rama. As lamentaçōes Individuais de Martin Fierro, ao contrário, se diluem ao sobressairem as notaçūes sobre o destino do gaúcho.

Se, como querem os autores de Ideologia \& política moderna, 31 "as ideologias surgem em condiçóes de crise" e se justificam na medida em que se constituem "refúgio contra incertezas", 32 em Los tres gauchos orientales (latentes) e em Martin Fierro (emergentes) elas se constituem motivos de reflexāo. E refletir é direito de cada cidadão. Optar, um dever. Levar à reflexão e à opção, obra de predestinados.

\section{REFERENCIAS BIBLIOGRAFICAS}

Christenson, Reo $M$. et aliji Ideologias \& politiea moedrna. SAo Paulo, IBRASA, 1974, 392 p.

Hernandez, Jose Martin Fierro. Buenos Aires, Ciordia, 1957, 225 p.

heRNaNdeZ, Jose. Mnrtin Fierro. Buenos Alres, Lasada, 1972.348 p.

LA POESIA polftica. Montevidéu, Cd. Arca, 1968. p. 243.76.

LUSSICH, Antonlo D. Los tres kmehog orientales. Montevideu. Ministério de Instrucción Pública y Previsión Social, 1964. $245 \mathrm{p}$.

NIEDERGANG, Marcel. Les 20 Amériques Latines. Paris, Seuil, 1969. 256 p. TACCA, Oscar. Ian voces de la novels. Madrid, Gredos, 1973. 205 D.

\section{Resumo}

Partindo de uma observação de Angel Rama foi constatado que em Los tres gauchos orientales de Lussich os narradores expressam na 1." pessoa plural um ideal político e na 1." pessoa singular um lirismo subjetivo e fracassado. Ao contrário, o monólogo de Martin Fierro, na obra de Hernandez, que se inica com uma 1." pessoa subje.

29 Ver CHRISTENSON, Reo M. e alii. Ideologias \& Politica moderna. Sáo Paulo, IBRASA, 1974. p. 17 .

30 Ibla., $p, 21$

31 Ibid p. 21

32 Ibld.. y. $2-$ 
tiva e fracassada, ao usar a 1.' pessoa plural traduz uma conscientização a respeito das tradicionais posiçōes da sociedade. Ao analisar esta mutação do narrador, a sua auto-definição como gaúcho versus os demais membros da sociedade, a sua posição na dicotomia resultante das forças que se the opõem, foi possivel constatar, também, que nāo se trata de uma simples opção de perspectiva narrativa, uma vez que nelas estão contidas, emergentes, as posições ideológicas de um tipo social.

\section{Resumen}

Con base en uma observación de Angel Rama fué posible constatar que en Los tres gauchos orlentales de Lussich los narradores exprimen en la primera persona del plural un ideal político y en la primera persona del singular un lirismo subjetivo y fracassado. Al contrário. el monólogo de Martin Fierro en la obra de Hernández, que se inicia en una primera persona subjetiva y fracasada, al usar la primera persona plural traduce una concientización a respecto de las tradicionales posiciones de la sociedad. Al analisar este cambio en la voz del narrador, su autodefinición como gaucho frente a los demás membros de la sociedad, su posición en la dicotomia que resulta de las fuerzas que se le oponen, también fué posible constatar que no se trata simplesmente de una opción narrativa pues que en ellas emergen las posiciones ideológicas de un tipo social. 